\title{
Determinants of state tobacco-control expenditures
}

\author{
Michael L. Marlow \\ Orfalea College of Business, California Polytechnic State University, \\ San Luis Obispo, CA 93407, USA \\ E-mail:mmarlow@calpoly.edu
}

While Centers for Disease Control and Prevention believe that most state governments under-fund tobacco-control programs, little is known about why large variation in spending exists between state governments. This study explores reasons for spending variation through an econometric model of per capita spending on tobacco-control programs that explores the effects of smoking prevalence while holding constant tobacco settlement funds, state budget deficits, and other factors that might also be expected to influence spending variation. Empirical evidence indicates no support for the hypothesis that states with high smoking prevalence spend more on tobacco-control than other states. This finding may be quite surprising to those working in areas of public health and clearly leads to many important policy questions regarding why the data indicate that funding does not appear to bear any relation to perceived public health problems as would be predicted if policymakers were following a 'rational needs' approach to funding.

\section{Introduction}

Controlling tobacco use has become an important policy issue addressed by state governments. State governments spent $\$ 883160197$ and $\$ 762338414$ in years 2001 and 2002, respectively, on tobacco-control programs. ${ }^{1}$ Centers for Disease Control and Prevention (CDC) have established recommended funding levels in Best Practices for Comprehensive Tobacco Control Programs (1999) and currently believe that actual (state and federal) spending in all states is a little over one-half of 'lower-bound' or minimum Best Practices spending recommendations. ${ }^{2}$ $\mathrm{CDC}$ believes that adequate funding of tobacco control programs would reduce the number of adults who smoke by promoting quitting, prevent young people from ever starting, reduce exposure to secondhand smoke, and identify and eliminate disparities in tobacco use among population groups.

Despite literature indicating effectiveness of tobacco control programs, little is known about how state spending decisions on tobacco-control programs are determined and, more specifically, why there exists substantial variation in funding of state programs. ${ }^{3}$ As described below, average per capita state funding was $\$ 3.18$ in 2001 and $\$ 3.27$ in 2002 , with ranges of $\$ 0-\$ 20.69$ in 2001 and $\$ 0-\$ 18.15$ in 2002. If variation can be shown to be

\footnotetext{
${ }^{1}$ CDC (1999). Arizona and Massachusetts did not provide data for 2002 because their budgets had not been finalized at the time the CDC's publication went to press.

${ }^{2}$ Best Practices spending is estimated based on nine program elements: community programs to reduce tobacco use; chronic disease programs to reduce the burden of tobacco-related diseases; school programs; enforcement; statewide programs; counter-marketing; cessation programs; surveillance and evaluation; and administration and management.

${ }^{3}$ See, for example, Hu et al. (1995a, b), Farrelly et al. (2003) and Tauras et al. (2005).
} 
systematically related to factors that reflect urgency of public health concerns, such as differences in smoking prevalence, then variation would appear to promote CDC's goal of controlling tobacco use within the country as a whole. If, for example, highspending states were also those with the highest prevalence of smoking, then funding variation might reflect an efficient allocation of funding resources. For instance, systematically spending more in states characterized by relatively high tobacco use and less in states with relatively low tobacco use might be justified if the goal is to lower national tobacco use toward some pre-determined goal.

This study seeks to determine the degree to which spending variation is systematically related to factors that reflect urgency of public health concerns. This study uses a newly-available and publicly-available data set on tobacco-control expenditures during 2001 and 2002 in which over $\$ 1.6$ billion were allocated. ${ }^{4}$ Reasons for this variation are explored through an econometric model of spending on tobacco-control programs that explores the independent effects of smoking prevalence while holding constant tobacco settlement funds, state budget deficits, and other factors that might also be expected to influence spending variation between states.

\section{Spending on Tobacco-Control Programs}

State spending on tobacco control programs comes from a variety of sources. In 2002, for instance, 46 states received more than $\$ 6$ billion in tobacco settlement revenues (Master Settlement Agreement), and the four states - Florida, Minnesota, Mississippi and Texas that settled independently with the tobacco industry also received substantial revenue. ${ }^{5}$ Settlement revenues were based on a formula that included smoking-attributable state Medicaid expenses. The Master Settlement Agreement did not dictate how funds were to be allocated, although the public health community had hoped that states would significantly expand funding of tobacco-control programs. Recent evidence, however, indicates that relatively few settlement dollars have gone toward tobacco-control and there is some perception that many of these dollars have gone toward closing state government deficits and costs associated with general health care programs. ${ }^{6}$ Keeler et al. (2004) argue that, in reaction to the Master Settlement Agreement of 1998, advertising by tobacco firms rose and partially offset (from 33 to $57 \%$ ) effects of higher cigarette prices thus suggesting that effects of the tobacco settlement on smoking prevalence are complicated to predict.

It should be understood, however, that an accounting of where tobacco settlement revenues have been allocated cannot provide a clear picture of overall state spending on tobacco-control. State governments fund tobacco control programs through a variety of general sources such as income and property taxes as well as from more specific revenue sources such as taxes on tobacco and alcohol. For example, 12 states appropriated \$14 million from general revenue to support tobacco control programs in 2002. ${ }^{7}$ Over $\$ 8$ billion in 2004 was collected in cigarette tax revenue in the 50 states and some of these dollars could also have funded tobacco-control programs. ${ }^{8}$

Government funds are fungible in the sense that an increase in funding from a specific revenue source such as the tobacco settlement may take place at the same time that funds from other sources rise, fall or remain the same. In other words, budgeting is dynamic in the sense that a change in funding from one source may trigger a change in another source. ${ }^{9}$ If a state allocates $\$ 50$ million from settlement funds to fund tobacco-control programs, the same state may at the same time raise or lower allocations from excise taxes, income taxes, or property taxes that result in increases, decreases or no changes in overall funding of tobacco-control programs. ${ }^{10}$ Total spending on tobacco-control is the correct metric to examine, not individual funding sources in this dynamic funding world. This discussion is not meant to argue that examination of how state governments allocate funds from the tobacco settlement, or from other sources such as excise taxes on tobacco, is not useful. Clearly, increased spending on tobacco-control must be funded from somewhere and

${ }^{4} \mathrm{CDC}(2001)$ and CDC (2002).

${ }^{5} \mathrm{GAO}(2004)$.

${ }^{6}$ See e.g. Gross et al. (2002), Johnson (2004) and Sloan et al. (2005).

${ }^{7}$ CDC (2002).

${ }_{9}^{8}$ Orzechowski and Walker (2004).

${ }^{9}$ Marlow and Shiers (1999) discuss this issue when they examine whether higher public funding of crime-related programs leads to changes in public education funding.

${ }^{10}$ Funding also comes from federal and private sources. Federal funding comes from CDC's Office on Smoking and Health that manages the National Tobacco Control Program and the Health and Human Service's (HHS) Substance Abuser and Mental Health Services Administration (SAMHSA); see CDC (2002). 
Table 1. Descriptive statistics: tobacco control expenditures per capita

\begin{tabular}{lcccc}
\hline & $\begin{array}{l}\text { State } \\
2001\end{array}$ & $\begin{array}{l}\text { Federal } \\
2001\end{array}$ & $\begin{array}{c}\text { State } \\
2002\end{array}$ & $\begin{array}{l}\text { Federal } \\
2002\end{array}$ \\
\hline Average (\$) & 3.18 & 0.56 & 3.27 & 0.73 \\
Median (\$) & 2.23 & 0.31 & 2.77 & 0.44 \\
Maximum (\$) & 20.69 & 2.70 & 18.15 & 3.17 \\
Minimum (\$) & 0 & 0.04 & 0 & 0.05 \\
SD & 3.97 & 0.57 & 3.42 & 0.68 \\
Sample size & 50 & 50 & 48 & 48 \\
\hline
\end{tabular}

public heath advocates naturally scrutinize current spending allocations from tobacco-related revenue sources. Data examined in this article - tobaccocontrol spending - reflect final overall funding of tobacco control programs as defined by CDC and reflect final allocations from multiple revenue sources. ${ }^{11}$

Table 1 displays descriptive statistics of per capita spending on tobacco-control programs in 2001 and 2002. Data are available for all 50 states in 2001 and 48 states in 2002. Funding estimates were not available at the time of publication for Arizona and Massachusetts. Average per capita state funding was $\$ 3.18$ in 2001 and $\$ 3.27$ in 2002, with ranges of $\$ 0$ (Connecticut, North Carolina, North Dakota, Pennsylvania and Tennessee) to $\$ 20.69$ (Ohio) in 2001 and $\$ 0$ (Tennessee) to \$18.15 (Ohio) in 2002. Median per capita state spending was \$2.23 in 2001 and \$2.77 in 2002. Average per capita federal funding was $\$ 0.56$ in 2001 and $\$ 0.73$ in 2002, with ranges of $\$ 0.04$ (California) to $\$ 2.70$ (Vermont) in 2001 and $\$ 0.05$ (Florida) to $\$ 3.18$ (Vermont) in 2002. Median per capita federal spending was $\$ 0.31$ in 2001 and $\$ 0.44$ in 2002 . The data therefore indicate substantial variation in state spending and that state spending dominates overall spending. The data are not disaggregated and we cannot single out various programs such as counter-advertising expenditures vs. counselling expenditures vs. any other spending category. This is unfortunate because substantial variation in how states allocate funds to various programs is likely and it would be useful to observe how states choose among competing spending options. Such information might prove useful in determining relative effectiveness of competing spending options in controlling tobacco use.

Gross et al. (2002) study state spending in 2001 and is the only empirical study that directly examines variation in state tobacco-control spending. Primary conclusions are that state health issues (e.g. Medicaid expenditures and proportion of the population without health insurance) exert little effect on state spending and therefore tobacco settlement funds represent a mostly untapped revenue source for expanding state tobacco-control programs. While this study examined numerous variables that might influence tobacco-control spending, the statistical techniques used do not lend themselves to estimating causal determinants of tobacco-control spending. Stepwise regression and Spearman's rank correlation were the two methods used to examine data. The stepwise regression process was based on the criteria that variables with $p \leq 0.10$ would be retained and, in effect, is a technique designed to maximize $R^{2}$ s of estimated equations. ${ }^{12}$ Stepwise regression is an exercise that, in effect, forces data to determine the model and is not very useful to test hypotheses stemming from theory involving a dependent variable and two or more independent variables. Estimation of Spearman's rank correlation coefficients is suitable for considering only the relationship between two variables and thus does not appear to be suitable for an investigation of why spending on tobacco-control varies widely between states.

\section{Modelling Determinants of State Tobacco-Control Funding}

Tobacco-control programs are, in theory, aimed at curbing smoking prevalence which suggests that an efficient allocation funds on the basis of smoking prevalence. That is, states with higher smoking prevalence would receive greater funding than states with lower prevalence as long as greater funding is believed to lower prevalence. Therefore, an efficient allocation of resources across states would yield a positive relation between funding and prevalence. This prediction is consistent within a world where

\footnotetext{
${ }^{11}$ CDC (2002) notes limitations to its data collection. Reported amounts exclude appropriations for multiple purposes that included an unspecified amount of funding for tobacco control. State spending data are based on appropriations, rather than expenditures, and expenditures may differ from appropriated amounts, because of delays in implementation, program cuts, or establishment of trusts or endowments.

${ }^{12}$ As Pindyck and Rubinfeld $(1991$, p. 88$)$ state: 'While stepwise regression can be useful in looking at data when there are a large number of possible explanatory variables, it is of little value when one is attempting to analyze a model statistically. The reason is that $t$ and $F$-tests consider the test of a null hypothesis under the assumption that the model is correctly specified.'
} 
resources are allocated within a central planning model whereby policymakers attempt to allocate resources toward highest-valued uses. ${ }^{13}$

A similar prediction would arise under a federalist system of state governments. State officials might also allocate more resources in states with higher prevalence because needs are presumably greater in these states than states with lower prevalence. For example, it is predictable that cold weather states spend more on snow removal than warm climate states since that's where the snow is. States with more smokers could then be predicted to spend more on tobaccocontrol than states with fewer smokers as long as policymakers are efficiently allocating resources under the 'rational needs' approach to funding and believe that greater funding lowers prevalence.

An important implication here is that there should be some clear pattern or order concerning tobaccocontrol funding when resources are allocated efficiently across states. This pattern is also not dependent upon resources being allocated by a central government because a federalist system of state governments would follow a similar pattern as long as they are interested in efficiently allocating resources with the goal of curbing smoking prevalence. States with high prevalence should therefore exhibit more spending on tobacco-control than states with low prevalence since otherwise it is as if snow removal does not bear any connection to climate. Moreover, even if states within a federalist system do not follow the 'rational needs' approach, the central government may promote the 'rational needs' approach to funding by granting funds to states on the basis of supporting a pattern whereby total - state and central funding is positively related to smoking prevalence.

Endogeneity is an issue of concern if the causal relationship between tobacco-control spending and smoking prevalence is actually two-way. While smoking prevalence may influence tobacco-control spending, another direction may be that tobaccocontrol spending influences smoking prevalence. Disentanglement of these two causal effects is a critical issue here because otherwise we cannot distinguish between two very different interpretations of the literature's finding that tobacco-control spending lowers tobacco use. ${ }^{14}$ While authors of previous studies have argued that tobacco-control spending causes lower tobacco use, a counterinterpretation is that lower smoking prevalence causes higher tobacco-control spending as consistent with the hypothesis that states with less tolerance for smoking (as indicated by relatively low smoking prevalence) will also fund tobacco-control programs more generously. Separation of these effects is essential when we wish to examine effectiveness of tobacco-control programs and whether the direction and magnitude of state spending on control programs should be altered. The possibility of two-way causality between tobacco-control spending and smoking prevalence is addressed by estimating models of tobacco-control spending with two-stage least squares. Ordinary least squares produces biased and inconsistent estimates of coefficients in the presence of simultaneity.

The following model of state spending on tobaccocontrol is estimated by two-stage least squares for each of 2 years, 2001 and 2002.

$\mathrm{FUND}_{i}=f\left(Y_{i}, \mathrm{TS}_{i}, \mathrm{UE}_{i}, \mathrm{DEBT}_{i}, \mathrm{FOUR}_{i}, \mathrm{SMOKER}_{i}\right) \leftarrow$

The first-stage equation is

$$
\begin{aligned}
& \mathrm{SMOKER}_{i}=f\left(Y_{i}, \mathrm{TS}_{i}, \mathrm{UE}_{i}, \mathrm{DEBT}_{i}, \mathrm{FOUR}_{i},\right. \\
&\left.\operatorname{POPULATION}_{i}, \mathrm{DENSITY}_{i}, \mathrm{TOBSTATE}_{i}\right) \leftarrow \\
&(2) \leftarrow
\end{aligned}
$$

The instruments for the first-stage estimation are all independent variables in Equation 1 except SMOKER $_{i}$ and the addition of the following variables: state population, urban density, and a dichotomous variable that equals one if the state has a significant tobacco manufacturing presence (Georgia, Kentucky, North Carolina, Ohio, South Carolina and Virginia) and zero otherwise. Variables are defined along with summary statistics in Table 2.

State per capita funding of tobacco-control programs $\left(\mathrm{FUND}_{i}\right)$ is obtained from the previously discussed CDC data set. State median income of a four-person family $\left(\mathrm{Y}_{i}\right)$ is obtained from the US

\footnotetext{
${ }^{13}$ An economically efficient allocation does not necessarily mean that states with high prevalence should spend more on control if, for instance, programs are not equally effective or when states have heterogeneous policy objectives. Differences in demographics across states might also lead to spending differences across states under a 'rational needs' approach. For example, Yen (2005) finds that smoking falls with education, but older smokers consume more cigarettes than younger smokers, in the USA. Goel and Nelson (2005) find significant differences in tobacco consumption across age and gender as well in the USA. Following the Bask and Melkersson (2004) argument that alcohol and cigarette consumption are simultaneous decisions, tobacco-control policy should perhaps also be influenced by alcohol consumption in states. Such differences might suggest, for instance, that state spending should differ according to age, gender and other characteristics of the population, even when states have similar overall smoking prevalence.

${ }^{14}$ See $\mathrm{Hu}$ et al.(1995a, b), Farrelly et al. (2003) and Tauras et al. (2005).
} 
Table 2. Summary statistics of variables, 2002

\begin{tabular}{|c|c|c|c|c|}
\hline Definition & Mean & Median & Minimum & Maximum \\
\hline POPULATION $_{i}=$ state population in thousands & 5747 & 4098 & 499 & 34988 \\
\hline DENSITY $_{i}=$ urban-percent of state population & $71.7 \%$ & 71.5 & 38.2 & 94.4 \\
\hline TOBSTATE $_{i}=1$ if tobacco-producing state $;=0$ otherwise & 0.12 & 0.0 & 0.0 & 1.0 \\
\hline $\mathrm{FUND}_{i}=$ state per capita funding of tobacco-control programs $(\$)$ & 3.27 & 2.77 & 0 & 18.15 \\
\hline $\mathrm{TS}_{i}=$ state per capita tobacco settlement funds $(\$)$ & 31.86 & 30.60 & 13.62 & 73.35 \\
\hline $\mathrm{UE}_{i}=$ state unemployment rate $(\%)$ & 5.32 & 5.40 & 3.3 & 7.6 \\
\hline $\mathrm{Y}_{i}=$ state median income of a four-person family $(\$)$ & $\$ 58633$ & $\$ 57624$ & $\$ 44947$ & $\$ 75505$ \\
\hline FOURSTATE $_{i}=$ for states with long-standing programs; $=0$ otherwise & 0.08 & 0.0 & 0.0 & 1.0 \\
\hline $\mathrm{DEBT}_{i}=$ state government per capita deficit or surplus $(\$)$ & $\$ 182.19$ & $\$ 134.74$ & $\$-295.74$ & $\$ 1171.72$ \\
\hline $\mathrm{SMOKER}_{i}=$ percent of adult population who smoke $(\%)$ & 23.41 & 23.15 & 12.70 & 32.60 \\
\hline
\end{tabular}

Census and is hypothesized to be positively related to tobacco-control spending based on the expectation that such funding is a 'normal' good - voters demand higher funding as their incomes rise. State per capita tobacco settlement funds $\left(\mathrm{TS}_{i}\right)$ is hypothesized to be positively related to tobacco-control spending based on expectation that some portion of these revenues would flow into tobacco-control programs. These data are reported in McKinley et al. (2003) and include funds by all states regardless of whether or not they participated in the Master Settlement Agreement. Inclusion of a dichotomous variable reflecting whether or not a state participated in the Master Settlement Agreement did not affect results of this article and so are not displayed here.

The state unemployment rate $\left(\mathrm{UE}_{i}\right)$ controls for the economic condition of states and is obtained from Census data. It is expected to negatively influence tobacco-control spending because higher values indicate greater concerns with income-stabilization concerns of state governments which then may cause states to lower funding of tobacco-control. If tobacco-control is viewed as a longer-term problem by state legislatures and governors, they may be willing to forgo some of its funding as unemployment rises. State government deficit or surplus per capita $\left(\mathrm{DEBT}_{i}\right)$ is included to control for the expectation that higher deficits indicate greater fiscal duress that results in lower spending on tobacco-control.

A dichotomous variable $\left(\mathrm{FOUR}_{i}\right)$ equals one for the four states (Arizona, California, Massachusetts and Oregon) with long-standing and comprehensive tobacco-control programs; and equals zero otherwise. These four states were early pioneers in tobaccocontrol programs since most states have only recently been funding programs in a comprehensive effort aimed at lowering tobacco use. ${ }^{15}$ It is expected that these four states will more generously fund state tobacco-control programs and so this variable is hypothesized to be positively related to tobaccocontrol spending.

The percent of the adult population who smoke $\left(\mathrm{SMOKER}_{i}\right)$ controls for the perceived need to fund tobacco-control by policymakers as well as public sentiment regarding smoking. Cigarette smoking is defined as persons who reported having smoked 100 or more cigarettes during their lifetime and who currently smoke every day or some days and is based on the Behavioural Risk Factor Surveillance System, a telephone survey of health behaviours of the civilian, noninstitutionalized US population, 18 years old and over. ${ }^{16}$ The expected sign on $\mathrm{SMOKER}_{\mathrm{i}}$ is ambiguous. The 'rational needs' allocation framework predicts that higher funding arises with greater needs as indicated by higher smoking prevalence and so state officials spend more on tobacco-control programs in states with more smokers. However, higher smoking prevalence may also indicate greater support for smoking and therefore less public sentiment that state governments should generously fund tobacco-control programs. This possibility is consistent with previous research showing that the probability that states pass laws prohibiting smoking in public places is influenced by factors such as whether states have significant degrees of tobacco-related jobs and smokers. Dunham and Marlow (2000) find that presences of a state smoking law are influenced by whether or not a state has a significant tobacco presence and Hersch et al. (2004) find that state smoking laws are responsive to voter

\footnotetext{
${ }^{15}$ CDC (2001) and CDC (2002).

${ }^{16}$ See CDC (2004).
} 
preferences in a state. These results suggest that, because states with relatively few smokers or tobaccorelated jobs are more likely to pass laws prohibiting smoking, states with relatively few smokers may be more likely to generously fund tobacco-control programs. Given the conflicting hypotheses, the sign on $\mathrm{SMOKER}_{i}$ is an empirical question to be resolved through data examination.

A measure of youth smoking was also considered as a control for public sentiment regarding smoking. State control efforts are presumably also directed at those initiating smoking, namely adolescents. Youth smoking was measured as percent of current cigarette smoking by students in grades 9-12 as defined by having smoked cigarettes on 1 or more of the 30 days preceding the survey. Data was obtained from CDC (2002) and was available for 46 states in 2002. Results are not displayed here because they did not differ from the case of adult smoking prevalence and because its use resulted in a smaller sample size.

Because the amount of settlement dollars per capita is derived through estimation of smoking-related Medicaid costs, it is possible that states with higher smoking prevalence rates are likely to receive more generous tobacco settlement allocations. That is, if smoking prevalence is directly related to settlement income, smoking prevalence and settlement funds may be collinear. However, simple correlation coefficients between smoking prevalence and state per capita settlement funds are 0.05 (2001) and 0.04 (2002) thus suggesting that multi-collinearity between $\mathrm{SMOKER}_{i}$ and $\mathrm{TS}_{i}$ is of little concern.
Measures of political party affiliation (dichotomous variable equal to one if a state had a democratic governor and zero otherwise, and share of population voting for a democratic presidential candidate) were included as explanatory variables to examine whether political differences explained any of the variation in tobacco-control spending across states. Results with these measures are not displayed here because they were not found to exert statistically significant effects on tobacco-control spending.

It is possible that there might be differential variance by size of state. Equations are estimated with SE and variances that are computed using White's (1980) covariance estimator which estimates the coefficient covariances in the presence of heteroskedasticity of unknown form. These estimates provided a slight gain in statistical significance of several variables over estimates using ordinary least squares and so these estimates are displayed in this article.

\section{Estimates of Tobacco-Control Spending Equations}

Table 3 displays two-stage least squares estimation of state tobacco control spending in 2001 and 2002. Three variables exhibit significant $t$-statistics (tobacco settlement funds, unemployment rates, and four-state dummy) in 2001 and four variables exhibit significant

Table 3. Two-stage least squares estimation of per capita state spending on tobacco- ontrol estimated coefficients

\begin{tabular}{|c|c|c|c|c|c|c|c|c|}
\hline & \multicolumn{2}{|l|}{ (1) } & \multicolumn{2}{|l|}{ (2) } & \multicolumn{2}{|l|}{ (3) } & \multicolumn{2}{|l|}{ (4) } \\
\hline & \multicolumn{4}{|l|}{2001} & \multicolumn{4}{|l|}{2002} \\
\hline & \multicolumn{2}{|l|}{ Smoker } & \multicolumn{2}{|c|}{ Tobacco-control } & \multicolumn{2}{|l|}{ Smoker } & \multicolumn{2}{|c|}{ Tobacco-control } \\
\hline Population & $2.7 \mathrm{E}-06$ & $(0.04)$ & & & -9.1 & $(1.24)$ & & \\
\hline Urban & -0.55 & $(1.60)$ & & & $0.08 * *$ & $(2.10)$ & & \\
\hline Tobacco-state & $2.21 * * *$ & $(1.83)$ & & & $3.08 *$ & $(2.76)$ & & \\
\hline Tobacco settlement funds per capita & 0.01 & $(0.34)$ & $0.09 * * *$ & $(1.92)$ & 0.03 & $(0.84)$ & $0.10^{*}$ & $(3.51)$ \\
\hline Unemployment & $0.99 *$ & $(3.08)$ & $-2.24 * * *$ & $(2.01)$ & $1.13 *$ & $(3.03)$ & $-1.10 * *$ & $(2.07)$ \\
\hline Median income & $1.4 \mathrm{E}-05$ & $(0.26)$ & $-3.6 \mathrm{E}-05$ & $(0.44)$ & $-4.3 \mathrm{E}-05$ & $(0.90)$ & $-4.4 \mathrm{E}-05$ & $(0.76)$ \\
\hline Four state & $-3.48 *$ & $(3.14)$ & $10.16^{* *}$ & $(2.38)$ & -1.94 & $(1.51)$ & $3.18 * * *$ & $(1.91)$ \\
\hline Deficit/surplus per capita & $0.003 * * *$ & $(1.69)$ & -0.004 & $(0.83)$ & -0.001 & $(0.23)$ & $0.003 * * *$ & $(1.99)$ \\
\hline smoker & & & 1.32 & $(1.50)$ & & & 0.08 & $(0.29)$ \\
\hline Constant & $21.52 *$ & $(8.54)$ & -18.66 & $(1.09)$ & $25.13 *$ & $(8.81)$ & 5.92 & $(0.76)$ \\
\hline Observations & 50 & & 50 & & 48 & & 48 & \\
\hline$F$-Statistic & 3.65 & & 1.71 & & 3.67 & & 1.99 & \\
\hline $\operatorname{Prob}(F$-statistic $)$ & 0.003 & & 0.143 & & 0.003 & & 0.09 & \\
\hline$R^{2}$ (adjusted) & 0.30 & & 0.00 & & 0.30 & & 0.11 & \\
\hline Mean dependent variable & 23.41 & & 3.18 & & 23.41 & & 3.27 & \\
\hline
\end{tabular}

Note: $* * *$ and $* * *$ Significance (two-tailed test) at 1, 5 and $10 \%$ levels, respectively.

$t$-statistics in parenthesis. 
$t$-statistics in 2002 (tobacco settlement funds, unemployment rates, four-state dummy, and deficit/ surplus). However, estimation does not exceed critical $F$-values using 2001 data and only barely exceeds the critical $F$-value using 2002 data $(p=0.09)$. Thus, we cannot reject the hypothesis that, as a group, the independent variables do not influence per capita state spending on tobacco-control in 2001. We can reject this hypothesis in 2002 , but only $11 \%$ of the variation in state spending on tobacco-control is explained in this model. The estimated coefficient on per capita tobacco settlement funds is 0.10 in 2002 and indicates that, for every additional settlement dollar, states would spend 10 cents of that dollar on tobacco-control.

First-stage estimation using 2001 data indicates that the share of the adult population that smokes is significantly influenced by whether or not the state produces tobacco (positive effect), unemployment rates (positive effect), whether the state has a longstanding tobacco-control program (negative effect), and the deficit/surplus variable (positive effect). Estimation using 2002 data indicates that the share of the adult population that smokes is significantly influenced by urbanization (positive effect), whether or not the state produces tobacco (positive effect), and unemployment rates (positive effect). Estimation in both years exceeds critical $F$-values thus indicating that we can reject the hypothesis that, as a group, the independent variables do not influence smoking prevalence.
Table 4 displays estimations of per capita state and federal spending on tobacco-control to examine whether our results change when we examine total spending on tobacco-control. An examination of total spending would be appropriate if state governments base spending plans on expectations of federal involvement. While one scenario is that states with relatively high values of state spending exhibit high prevalence to solicit federal funds through matching grant and other types of federal programs, it is also possible that state policymakers might view federal spending more as a substitute for state spending. Federal spending decisions might also somehow smooth out state spending decisions in the sense that states with greater needs - such as higher smoking prevalence - receive greater federal spending support. This latter possibility does not appear to be operative because simple correlations between smoking prevalence and per capita federal spending are less than $10 \%$ in both years.

Table 4 displays two-stage least squares estimation of total (state and federal) tobacco control spending in 2001 and 2002. The same variables exhibit significant $t$-statistics as before in estimations of state tobacco-control spending. We still cannot reject the hypothesis that, as a group, the independent variables do not influence per capita state and federal spending on tobacco-control in 2001, but we can reject this hypothesis in 2002. The estimated coefficient on per capita tobacco settlement funds is 0.11 in 2002 and indicates that, for every additional

Table 4. Two-stage least squares estimation of per capita state and federal spending on tobacco-control estimated coefficients

\begin{tabular}{|c|c|c|c|c|c|c|c|c|}
\hline & \multicolumn{2}{|l|}{ (1) } & \multicolumn{2}{|l|}{$(2)$} & \multicolumn{2}{|l|}{ (3) } & \multicolumn{2}{|l|}{ (4) } \\
\hline & \multicolumn{4}{|l|}{2001} & \multicolumn{4}{|l|}{2002} \\
\hline & \multicolumn{2}{|l|}{ Smoker } & \multicolumn{2}{|c|}{ Tobacco-control } & \multicolumn{2}{|l|}{ Smoker } & \multicolumn{2}{|c|}{ Tobacco-control } \\
\hline Population & $2.7 \mathrm{E}-06$ & $(0.04)$ & & & -9.1 & $(1.24)$ & & \\
\hline Urban & -0.05 & $(1.60)$ & & & $0.08 * *$ & $(2.10)$ & & \\
\hline Tobacco-state & $2.21 * * *$ & $(1.83)$ & & & $3.08 *$ & $(2.76)$ & & \\
\hline Tobacco settlement funds per capita & 0.01 & $(0.34)$ & $0.10 * *$ & $(2.59)$ & 0.03 & $(0.84)$ & $0.11 *$ & $(3.38)$ \\
\hline Unemployment & $0.99 *$ & $(3.08)$ & $-1.89 * * *$ & $(2.00)$ & $1.13^{*}$ & $(3.03)$ & $-1.53 * *$ & $(2.56)$ \\
\hline Median income & $1.4 \mathrm{E}-05$ & $(0.26)$ & $-5.0 \mathrm{E}-05$ & $(0.65)$ & $-4.3 \mathrm{E}-05$ & $(0.90)$ & $-2.6 \mathrm{E}-05$ & $(0.41)$ \\
\hline Four state & $-3.48^{*}$ & $(3.14)$ & $7.07 * *$ & $(2.31)$ & -1.94 & $(1.51)$ & $3.97 * *$ & $(2.12)$ \\
\hline Deficit/surplus per capita & $0.003 * * *$ & (1.69) & -0.001 & $(0.14)$ & -0.001 & $(0.23)$ & $0.004 * *$ & $(2.28)$ \\
\hline Smoker & & 0.76 & $(1.16)$ & & 0.20 & $(0.68)$ & & \\
\hline Constant & $21.52 *$ & $(8.54)$ & -6.05 & $(0.52)$ & $25.13^{*}$ & $(8.81)$ & 5.92 & $(0.76)$ \\
\hline Observations & 50 & & 50 & & 48 & & 48 & \\
\hline$F$-Statistic & 3.65 & & 1.76 & & 3.67 & & 2.56 & \\
\hline $\operatorname{Prob}(F$-statistic $)$ & 0.003 & & 0.130 & & 0.003 & & 0.03 & \\
\hline$R^{2}$ (adjusted) & 0.30 & & 0.00 & & 0.30 & & 0.15 & \\
\hline Mean dependent variable & 23.41 & & 3.73 & & 23.41 & & 4.00 & \\
\hline
\end{tabular}

Note: $*, * *$ and $* * *$ Significance (two-tailed test) at 1,5 and $10 \%$ levels, respectively. $t$-statistics in parenthesis. 
settlement dollar per capita, states would spend 11 cents of that dollar on tobacco-control. First-stage estimations are identical to those previously discussed in Table 3.

\section{Conclusions}

This study finds no evidence that tobacco-control spending by state governments in 2001 was influenced by tobacco settlement funds, unemployment rates, median state income, prevalence of smokers, whether or not a state had a long-standing tobacco-control program, or by size of state government deficits or surpluses. The empirical evidence thus indicates little to no information on why tobacco-control spending varied between states in 2001. In 2002, however, evidence for four significant influences is indicated: tobacco settlement funds exerted positive influences, unemployment rates exerted negative influences, state with long-standing programs exerted positive influences, and deficits exerted positive influences on tobacco-control spending. But, the model explains no more than $15 \%$ of spending variation in 2002 . In sum, examined variables explain very little of the variation in over $\$ 1.6$ billion of spending in 2001 and 2002.

The main empirical finding that there is very little or no correlation between tobacco-control and smoking prevalence across states should be of concern to those who believe in a 'rational needs' approach to public funding. This result is consistent with studies showing that higher public health spending does not necessarily lead to better health outcomes. Berger and Messer (2002) examine the link between public financing of health spending and health outcomes across OECD countries and finds that health outcomes are inversely related to the proportion of their expenditures that are publicly financed. Self and Grabowski (2003) conclude that, while higher spending may raise health outcomes in middle- to less-developed countries, there is little evidence that higher public spending on health improves health outcomes in wealthy countries.

The results may be quite surprising to those working in areas of public health and clearly leads to many important policy questions regarding why the data indicate that funding does not appear to bear any relation to perceived public health problems as would be predicted if policymakers were following a 'rational needs' approach to funding. As previously discussed, this empirical result might indicate that the 'rational needs' approach to funding is somehow cancelled-out by efforts of groups who are not motivated to curb smoking prevalence. Such groups may include smokers themselves as well as businesses that profit from sales of cigarettes such as retailers, tobacco manufactures, and bars and taverns. Some state governments may as well experience mixed feelings regarding tobacco-control when they rely on tobacco taxes to fund general government programs. In other words, in states with high prevalence the tendency to spend more due to health concerns may be cancelled out by those with opposing interests since it is more difficult to organize a lobby opposed to smoking in states with many smokers. Weak or nonexistent correlation between tobacco-control funding and smoking prevalence supports this explanation of why the funding data do not appear to be based on the 'rational needs' approach.

If tobacco-control dollars are not following the problem of smoking prevalence, is it possible that dollars are following something else? One possibility is that funding follows political support in some states in the sense that more politicians and voters sympathetic to tobacco-control are found in states with low smoking prevalence and so it is easier to raise money in states with fewer smokers. This possibility might mean that the fact that a state spends more and has low smoking prevalence may not signify the effectiveness of tobacco-control programs, but rather that it is just easier to raise funds in a low-prevalence state. Funding unrelated to smoking prevalence may then be consistent with a world where some states follow the 'rational needs' approach and other states have funding levels influenced more by those opposed to controlling tobacco use. A similar question is whether states with higher tobacco taxes may also be causing lower smoking prevalence or does lower prevalence simply make it easier to raise tobacco taxes in some states? Better understanding of the determinants of tobaccocontrol allocations across states and whether or not these allocations are causally-related to smoking behaviour are issues that deserve further attention. The results of this study would appear to suggest the importance of re-examining recent proposals by the $\mathrm{CDC}$ for substantial increases in tobacco-control spending in light of the evidence showing little to no connection between what states spend on tobaccocontrol and levels of smoking prevalence.

\section{Acknowledgement}

William Orzechowski, Alden Shiers, Takis Papakyriazis and an anonymous referee provided many helpful comments. 


\section{References}

Bask, M. and Melkersson, M. (2004) Rationally addicted to drinking and smoking?, Applied Economics, 36, 37381.

Berger, M. C. and Messer, J. (2002) Public financing of health expenditures, insurance, and health outcomes, Applied Economics, 34, 2105-13.

Centers for Disease Control and Prevention (CDC), Best Practices for Comprehensive Tobacco Control Programs-August 1999. Atlanta: US Department of Health and Human Services, Centers for Disease Control and Prevention, National Center for Chronic Disease Prevention and Health Promotion, Office on Smoking and Health, 1999.

Centers for Disease Control and Prevention (CDC), Tobacco Control State Highlights 2001: impact and Opportunity. Atlanta, GA: Department of Health and Human Services, Centers for Disease Control and Prevention, National Center for Chronic Disease Prevention and Health Promotion, Office on Smoking and Health, 2001.

Centers for Disease Control and Prevention (CDC), Tobacco Control State Highlights 2002: impact and Opportunity. Atlanta, GA: Department of Health and Human Services, Centers for Disease Control and Prevention, National Center for Chronic Disease Prevention and Health Promotion, Office on Smoking and Health, 2002.

Centers for Disease Control and Prevention (CDC) (2004) Cigarette smoking among adults - United States, 2002, Morbidity and Mortality Weekly Report, 53, 427-31.

Dunham, J. and Marlow, M. L. (2000) The effects of smoking laws on seating allocations of restaurants, bars and taverns, Economic Inquiry, 38, 151-7.

Farrelly, M. C., Pechacek, T. F. and Chaloupka, F. J. (2003) The impact of tobacco control program expenditures on aggregate cigarette sales: 19812000, Journal of Health Economics, 22, 843-59.

General Accounting Office (GAO) (2004) Tobacco Settlement. States' Allocations of Fiscal Year 2003 and Expected Fiscal Year 2004 Payments.

Goel, R. K. and Nelson, M. A. (2005) Tobacco policy and tobacco use: differences across tobacco types, gender and age, Applied Economics, 37, 765-71.

Gross, C. P., Soffer, B., Bach, P.B., Rajkumar, R. and Forman, H. P. (2002) State expenditures for tobaccocontrol programs and the tobacco settlement, New England Journal of Medicine, 347, 1080-6.

Hersch, J., Del, R., Alison, F. and Kip Viscusi, W. (2004) Voter preferences and state regulation of smoking, Economic Inquiry, 42, 455-68.
Hu, T.-W., Sung, H.-Y. S. and Keeler, T. E. (1995a) The state antismoking campaign and the industry response: the effects of advertising on cigarette consumption in California, American Economic Review, Papers and Proceedings, 85, 85-90.

Hu, T.-W., Sung, H.-Y. S. and Keeler, T. E. (1995b) Reducing Cigarette Consumption in California: Tobacco Taxes vs. an Anti-Smoking Media Campaign, American Journal of Public Health, 85, 1218-22.

Johnson, C. L. (2004) The state of the tobacco settlement: are settlement funds being used to finance state government budget deficits? A research note, Public Budgeting and Finance, 24, 113-23.

Keeler, T. E., Hu, T.-W., Ong, M. and Sung, H.-Y. (2004) The US national tobacco settlement: the effects of advertising and price changes on cigarette consumption, Applied Economics, 36, 1623-9.

Orzechowski, W. and Walker, R. J. (2004) The Tax Burden on Tobacco: Historical Compilation,Volume 39, 2004. Orzechwski and Wallker, Arlington, VA.

Marlow, M. L. and Shiers, A. (1999) Do law enforcement expenditures crowd-out public education expenditures?, Applied Economics, 31, 255-66.

McKinley, A., Dixon, L. and Devor, A. (2003) State Management and Allocation of Tobacco Settlement Revenue, National Conference of State Legislatures. MMWR Weekly (2004) State-specific prevalence of current cigarette smoking among adults - United States, 2003, 53,1035-37.

Pindyck, R. S. and Rubinfeld, D. L. (1991) Econometric Models and Economic Forecasts, 3rd edn, McGrawHill, Inc., New York.

Self, S. and Grabowski, R. (2003) How effective is public health expenditure in improving overall health? A cross-country analysis, Applied Economics, 35, 835-45.

Sloan, F. A., Allsbrook, J. S., Madre, L. K., Masselink, L. E. and Matthews, C. A. (2005) States' allocations of funds from the tobacco master settlement agreement, Health Affairs, 24, 220-7.

Tauras, J. A., Chaloupka, F. J., Farrelly, M. C., Giovino, G. A., Wakefield, M., Johnston, L. D., O'Malley, P. M., Kloska, D. D. and Pechacek, T. F. (2005) State tobacco control spending and youth smoking, American Journal of Public Health, 95, 338-44.

White, H. (1980) A heterokedasticity-consistent covariance matrix estimator and a Direct test for heteroskedasticity, Econometrica, 48, 827-39.

Yen, S. T. (2005) Zero observations and gender differences in cigarette consumption, Applied Economics, 37, 1839-49. 